\title{
Properties of clays reinforced PLA nanocomposites by melt extrusion technique
}

\author{
Tika Paramitha a, b, Vita Wonoputri b, Daniel Steven D Sitompul c, Hyung Woo Lee ${ }^{\text {b, d }}{ }^{\text {, Johnner P }}$ \\ Sitompul ${ }^{b, *}$ \\ a Department of Chemical Engineering, Faculty of Engineering, Universitas Sebelas Maret, 57126, Surakarta, Central Java, Indonesia \\ ${ }^{b}$ Department of Chemical Engineering, Faculty of Industrial Technology, Institut Teknologi Bandung, 40132, Bandung, West Java, Indonesia \\ c Department of Electrical Engineering, School of Electrical Engineering and Informatics, Institut Teknologi Bandung, 40132, Bandung, West Java, \\ Indonesia \\ d Center for International Affairs, National Research Foundation of Korea, 25, Heolleungno, Sepcho-gu, Seoul, 06792, Korea
}

* Corresponding author: tikaparamitha@staff.uns.ac.id

\section{Article history}

Received 3 Mac 2019

Revised 28 October 2019

Accepted 20 January 2020

Published Online 17 August 2020

\begin{abstract}
Nanocomposites were prepared by melt extrusion technique using single screw extruder and subsequent hot compression. In this work, poly lactic acid-clay nanocomposites were obtained using two types of clays, namely commercial montmorillonite (Cloisite 30B) and commercial bentonite. Nanocomposites were prepared at low clay composition of $0.5,1,3$, and $5 \mathrm{wt} . \%$ of clays. From XRD spectra, the partially exfoliation of nanoclay layers were occurred during melting extrusion. It resulted in improvement of mechanical properties, such as Young's modulus, tensile strength, and elongation at break. The highest tensile strength was obtained by the addition of $0.5 \mathrm{wt} . \%$ commercial bentonite increasing about $23.25 \%$ compared to the neat PLA. The increasing composition of clays revealed a decrease in mechanical properties due to filler-filler interaction. Furthermore, water absorption of nanocomposites up to ` 1 wt.\% of clays better than the neat PLA. Biodegradability was enhanced in the presence of higher clay composition due to high hydrophilicity of clay, high water uptake, and high interactions. The results show that the weight loss of the neat PLA and the nanocomposite with the addition of 5 wt. $\%$ of Cloisite $30 \mathrm{~B}$ are $4.0 \%$ and $10.8 \%$, respectively.
\end{abstract}

Keywords: nanocomposites, PLA, extrusion, biodegradability, mechanical properties

(C) 2020 Penerbit UTM Press. All rights reserved

\section{INTRODUCTION}

Global plastic consumption is more than 200 million tons with an annual growth of $5 \%$ (Siracusa et al., 2008). The use of plastics has been increasing steadily in line with the rising of human population. Most of plastics are produced from fossil, such as polypropylene, polyethylene, polystyrene, and polyvinyl chloride. Plastic buildup creates environmental problems due to long degradation times of plastics (Phuong et al., 2012). Further, raw materials of plastic are non-renewable fossil fuel sources and hence plastic production processes accumulates high carbon dioxide footprints. Based on these problems, it is necessary to develop new materials produced from renewable resources to preserve the environment, namely biopolymers.

Poly lactic acid (PLA) is extensively researched and regarded as a promising biodegradable polymer due to its several advantages, such as environmentally friendly, biocompatible, and easy to process (Awal et al., 2015). However, neat (unmodified) PLA has limitations, such as poor toughness, slow degradation rates (Farah et al., 2016), and poor water barrier properties (Molinaro et al., 2013). Fortunately, it has been reported the addition of fillers to the PLA matrix, such as nanoclays and cellulose fibers, can help in overcoming these limitations (Ozdemir et al., 2016).

One of the most abundant clays in Indonesia is bentonite. Based on the work of Ollier et al. (2013), neat bentonite could be modified using tributyl hexadecyl phosphonium bromide and octadecyl ammonium chloride. The results showed that mechanical properties of unsaturated polyester matrix increase with the addition of modified clays. Furthermore, there are other commercial organomodified clays, such as Cloisite 30B. Zaidi et al. (2010) studied nanocomposites of Cloisite 30B and PLA matrix produced significant increase of Young's modulus of nanocomposites. In brief, the enhancement of Young's modulus due to incorporation clay that indicate degree of intercalation and exfoliation resulting in greater interfacial area between clays and polymer chains in the PLA matrix. The effects of addition of 4 wt.\% of montmorillonite (SBE4) on PLA matrix were reported by Ray et al. (2003). In the first month, the same weight loss and degree of hydrolysis were obtained for the neat PLA and PLA/SBE4 nanocomposites. However, the weight loss of PLA/SBE4 nanocomposites was higher than the neat PLA after 
one month. Thus, the biodegradation rate of nanocomposites was faster than the neat PLA.

Melt extrusion technique is one of the most widely used technique for preparation of nanocomposite. Melt extrusion technique gives good distribution of the clay in the matrix, which can improve the nanocomposite properties. In an earlier study, Ray et al. (2003) conducted a study on the addition of organically modified synthetic fluorine mica (OMSFM) into PLA by simple melt extrusion. The results of nanocomposites structure were intercalated and exfoliated structures. The mechanical properties of PLA/OMSFM nanocomposites are better than neat PLA.

In this study, nanocomposites were produced using melt extrusion technique with varying nanoclays, commercial bentonite from oleochemical industry and commercial Cloisite $30 \mathrm{~B}$ as comparison. In general, the objective of this research was to identify the influence of the clays on structures, mechanical properties, and biodegradability of the PLA-clay nanocomposites.

\section{EXPERIMENTAL}

\section{Materials}

Poly lactic acid (PLA) was supplied by Ingeo 2003D, Nature Work, USA. Cloisite 30B was purchased by Southern Clay Products and commercial bentonite were supplied by an oleochemical Industry, Jakarta, Indonesia.

\section{Preparation of Nanocomposite}

PLA and clays (Cloisite 30B or commercial bentonite) were mixed using a magnetic stirrer in a beaker with variable composition of clays $(0.5 ; 1 ; 3$; and 5 wt.\%). Afterwards, PLA and clays were compounded by a single-screw extruder with screw dimension $35 \mathrm{~cm}$ x $22 \mathrm{~mm}$ (LxD) placed inside a $23 \mathrm{~mm}$ inner diameter barrel heated with electrical source and the barrel surface was controlled at $170^{\circ} \mathrm{C}$. The single-screw extruder is shown in Fig. 1. The flow of material was about $0.3 \mathrm{~kg} / \mathrm{h}$ and the rotation speed was $100 \mathrm{rpm}$. The residence time was about $45 \mathrm{~s}$. The extruded compound was then pelletized after coming out from the extruder. Pellet was pressed using compression hot press molding machine at $170^{\circ} \mathrm{C}$ for 45 minutes under a pressure of $10 \mathrm{MPa}$. The hot-pressing process was divided into three sections, pre-heating, pressing, and cooling with duration 15, 40, and 20 minutes, respectively.

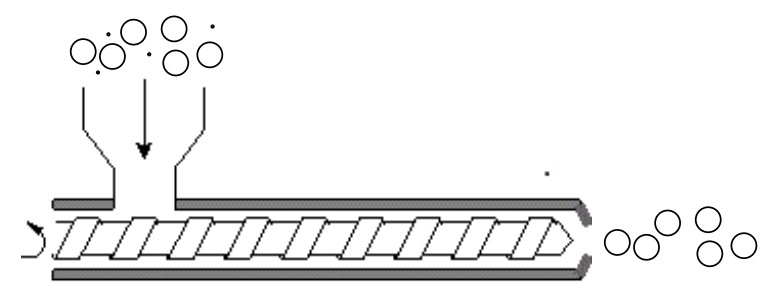

Fig. 1 Schematic diagram for melt extrusion technique.

\section{Characterization}

XRD characterization: XRD patterns of nanocomposites were obtained using a $\mathrm{CuK} \alpha$ radiation with Rigaku Smartlab diffractometer. XRD analysis was operated at $45 \mathrm{kV}, 30 \mathrm{~mA}$, and room temperature. In addition, the scanning rate was $20 \%$ minute. The interlayer distance was calculated using Bragg's equation:

$\mathrm{n} \lambda=2 \mathrm{~d} \sin \theta$

where $\lambda$ is the wavelength of the X-ray radiation $(0.1546 \mathrm{~nm}), \mathrm{d}$ is the interlayer distance, and $\theta$ is the measured diffraction angle.

Mechanical properties: The tensile tests were performed using the ASTM D683 type IV on universal testing machine (RTF-1310) equipped with a $10 \mathrm{kN}$ load cell and a $2 \mathrm{~mm} / \mathrm{min}$ crosshead speed.

Water absorption: The dimension of samples was $5 \mathrm{~cm} \mathrm{x} 1$ $\mathrm{cm} x$ thickness. Then, the samples were dried and immersed in water at room temperature for 7 days. The samples were gently wiped to remove excess moisture before being weighed. The water absorption was calculated as reported by Chow et al. (2014):

Percentage of water absorption $=\frac{W_{w}-W_{d}}{W_{d}} \times 100$

where $w_{w}$ denotes mass of the sample at time $\mathrm{t}$ and $w_{d}$ denotes initial mass of the sample (dried), respectively.

Biodegradability: The samples were buried in compost instrument (livestock manure) at $58^{\circ} \mathrm{C}$ for 10 days. Then, the weight reduction was determined. Parameters such as relative humidity and type of microorganisms were not carried out to control (Ray et al., 2003).

\section{RESULTS AND DISCUSSION}

\section{X-Ray diffraction pattern}

Based on Fig. 2., the peak of nanocomposites $\left(4.96^{\circ}\right)$ is comparable as the peak of Cloisite $30 \mathrm{~B}\left(4.90^{\circ}\right)$. Furthermore, commercial bentonite has the peaks of $5.88^{\circ}$ and $5.91^{\circ}$ for its nanocomposites. The most significant feature of the nanocomposite is found in the low 2 theta range indicating the clay structure (Lai et al., 2014). The same peak of nanocomposites and clays may suggest the possibility of formation of partially exfoliation. Based on calculation using Bragg's equation, the interlayer distance of Cloisite 30B is 1.81 $\mathrm{nm}$. Moreover, the interlayer distance of PLA-Cloisite 30B nanocomposites are $1.79 \mathrm{~nm}$ and $1.79 \mathrm{~nm}$ for the addition of 1 wt.\% of Cloisite 30B and 5 wt.\% of Cloisite 30B, respectively. Commercial bentonite has the 2 theta value of $5.88^{\circ}$ and the interlayer distance is $1.51 \mathrm{~nm}$. The interlayer distance of PLAcommercial bentonite is $1.50 \mathrm{~nm}$. Besides, there is the peak of PLA-commercial bentonite shifting to left side at the $2 \theta$ value of $3.97^{\circ}$. The interlayer distance of commercial bentonite in the polymer matrix also increases to $2.23 \mathrm{~nm}$, which is caused by the diffusion of polymer into commercial bentonite layer. 


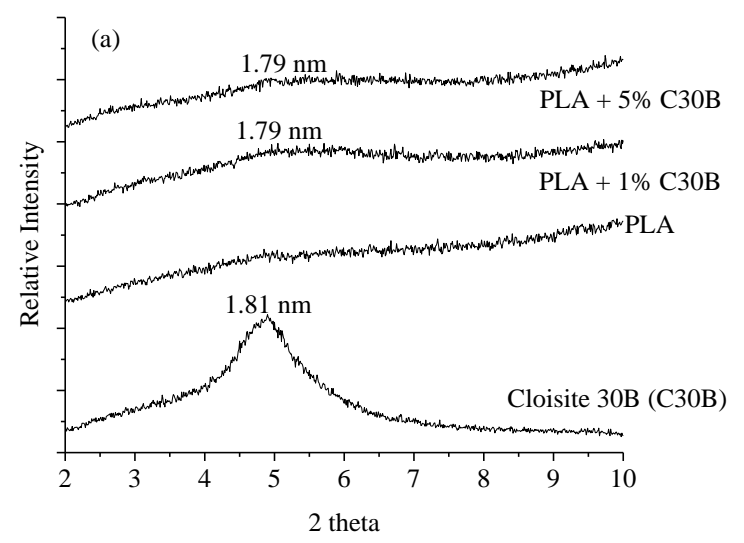

(a)

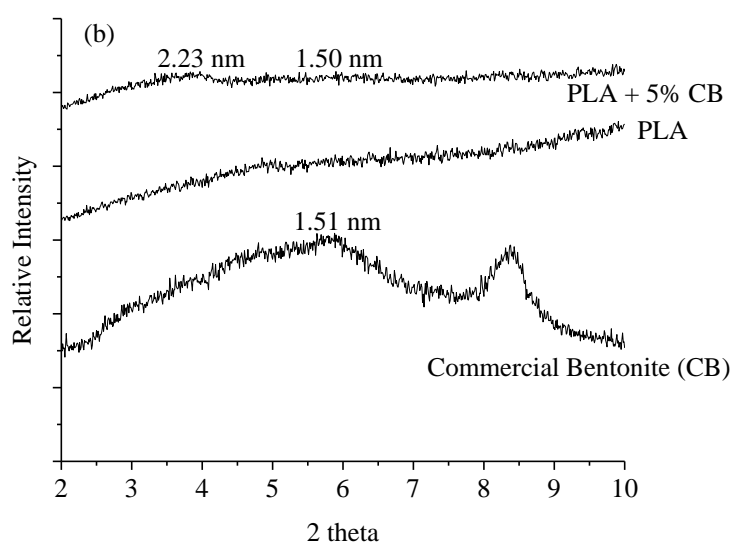

(b)

Fig. 2 XRD pattern of (a) Cloisite 30B and (b) commercial bentonite.

Based on XRD analysis, nanocomposite structures have reached partially exfoliation. This is because the silicate layer has not been dispersed uniformly on the nanocomposite. Complete exfoliation occurs when clay layer is separated from one another and distributed/dispersed in a matrix. The ideal morphology is achieved when no peak is observed in XRD pattern, which is owing to the absence of regular distance on the platelet clay. The incomplete distribution of clays in the nanocomposite is probably due to the short residence time (Paramitha et al., 2018). In this study, the residence time of PLA and clays is about $45 \mathrm{~s}$ in single screw extruder.

\section{Mechanical properties}

Mechanical properties are important properties for plastic materials because its use involves mechanical loads. The mechanical properties analyzed in this study are tensile strength, Young's modulus, and elongation at break. Fig. 3 (a) shows the tensile strength of nanocomposites affected by the composition of clay. In this study, nanocomposites with the addition of 1 wt. $\%$ of Cloisite $30 \mathrm{~B}$ had greater tensile strength compared to 0.5 wt. $\%, 3$ wt. $\%$, and 5 wt. $\%$ of Cloisite 30B. However, Pirani et al. (2014) conducted research that the addition of $2 \mathrm{wt} . \%$ of Cloisite 30B has the greatest yield strength. In addition, PLAcommercial bentonite nanocomposites have the greatest tensile strength with the addition of $0.5 \mathrm{wt} . \%$ of commercial bentonite. In comparison with the neat PLA, the tensile strength of $1 \mathrm{wt} \%$ of Cloisite 30B-PLA nanocomposite and $0.5 \mathrm{wt} \%$ of commercial bentonite-PLA nanocomposite increase about $18.59 \%$ and $23.25 \%$, respectively.

Fig. 3 (b) shows an increasing in Young's modulus due to the addition of clays. The neat PLA has Young's modulus of
1328.40 MPa. The Young's modulus of nanocomposites with the addition of 3 wt. $\%$ of Cloisite 30B increase about $8.11 \%$ $(1436.10 \mathrm{MPa})$. The Young's modulus of nanocomposites with the addition of commercial bentonite of $3 \mathrm{wt} . \%$ is $1655.30 \mathrm{MPa}$, with the improvement nearly $24.61 \%$ than the neat PLA. Moreover, Fig. 3 (c) shows the elongation at break of the nanocomposites. The elongation at break slightly increase at low clay composition. However, the elongation at break of the blends decrease as clay content more than $1 \mathrm{wt} . \%$ and $0.5 \mathrm{wt} \%$ for Cloisite $30 \mathrm{~B}$ and commercial bentonite, respectively. The results reveal that the more fillers increase the brittleness in the nanocomposites.

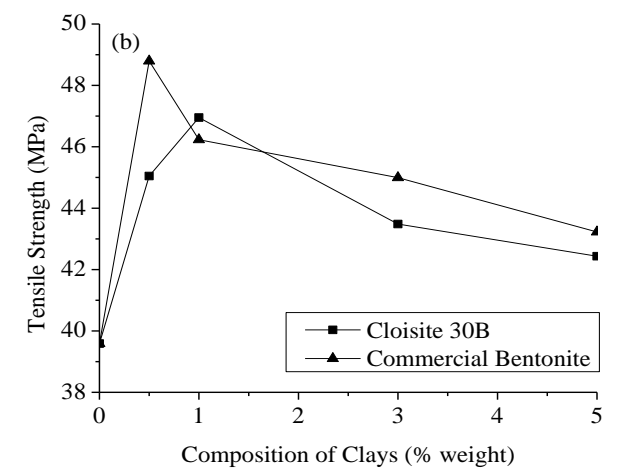

(a)

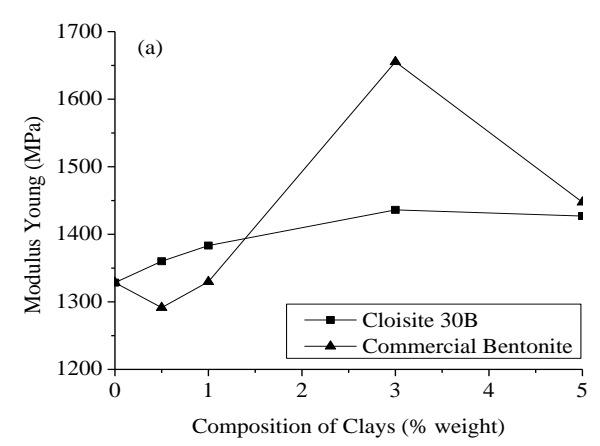

(b)

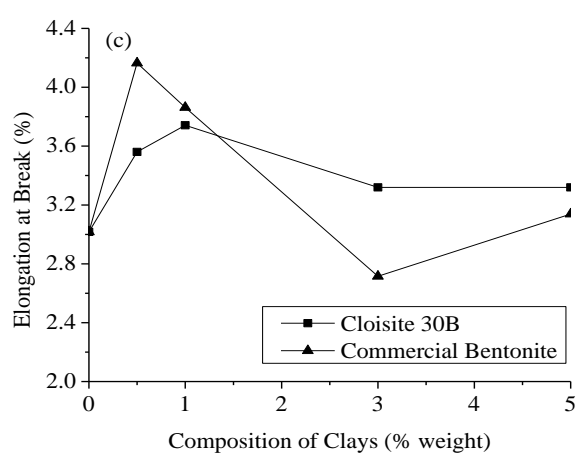

(c)

Fig. 3 Effect of clay composition on (a) tensile strength, (b) Young's modulus, and (c) elongation at break of PLA-Cloisite 30B and PLAcommercial bentonite nanocomposites.

The improvement in mechanical properties by incorporating low clay composition due to the dispersion degree of clay in the matrix, resulting in a greater clay-PLA interfacial area (Zaidi et al., 2010). The increasing of the clay interfacial area with the polymer matrix leads to better stress transfer. Tensile strength is mainly controlled by the effectiveness of the clay to transfer stress at the interface of matrix and filler (Rahman et al., 2018). However, in Fig. 3, it is shown that as the amount of clay 
increases, the mechanical properties will decrease. Thus, the dispersion of clay in the matrix is better at low clay composition.

The role of clay as reinforcing in nanocomposite is lower at high clay composition because of the clay platelets being stacked. As high addition of clay occurs, filler-filler interaction producing local stress concentration and mechanical properties decrease (Lai et al., 2017). Lee et al. (2007) reported HDPE/Cloisite 20A nanocomposites had better mechanical properties than the neat HDPE, especially in Young's modulus. Young's modulus increases from $177 \mathrm{MPa}$ to $197 \mathrm{MPa}$ with the addition of 1 wt.\% of Cloisite 20A. In this study, the improvement in Young's modulus up to $3 \mathrm{wt} . \%$ of clay. The delamination of clay become more difficult above an optimum clay composition. Thus, the high clay composition induces the aggregation of clay leading to a decrease in the Young's modulus (Chow et al., 2004). The stiffness of nanocomposites also increases due to the addition of clay.

\section{Water absorption properties}

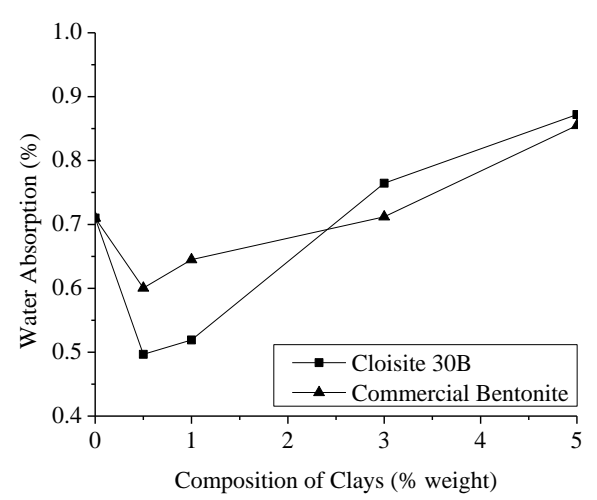

Fig. 4 Effect of water absorption of PLA-Cloisite 30B and PLAcommercial bentonite nanocomposites with variable composition of clays.

Fig. 4 shows the addition of clay affecting the water absorption properties. Water absorption decreases when adding clay up to $1 \mathrm{wt}$.\% compared to the neat PLA. The tortuous path of nanocomposite will increase with the addition of filler, which increase the distance water molecules through nanocomposite. On the other hand, the partially exfoliation of silicate layer can decrease the distance of water molecules. This makes more silicate groups interact with water molecules (Chow et al., 2014) and the nanocomposite absorbs more water at high composition of clay. At lower composition of clay, less than 1 wt.\%, commercial bentonite absorbs more water compared with Cloisite 30B, and quite comparable for higher clay composition, above 2.5 wt.\%. Water absorption influence the mechanical and physical properties of materials. According to Yew et al. (2005), water act as plasticizer and/or hydrolysis agent. Thus, the highwater absorption would probably increase the biodegradability of materials.

\section{Biodegradability}

Characterization of biodegradability was conducted in compost instrument using microbes from livestock manure. Livestock manure contains microorganism that causes biodegradation process. Environmental factors such as humidity, $\mathrm{pH}$, oxygen, nutrients, and type of microorganisms were not carried out to control. According to Bikiaris et al. (2013), the complex process of enzymatic degradation involves the absorption of water, enzymatic attack on the surface of polyester, cleavage of ester in macromolecular chains, hydrolysis and formation of oligomer fragments, erosion of surface, diffusion and consumption of soluble oligomers, and formation of carbon dioxide and water. Biodegradation test was conducted at $58^{\circ} \mathrm{C}$. In the case of hydrolytic degradation tests, the biodegradation was carried out at two different temperatures, which were at $37^{\circ} \mathrm{C}$ and $58^{\circ} \mathrm{C}$ (Bikiaris et al., 2013). The weight changes were low when the samples were degraded at $37^{\circ} \mathrm{C}$ within 8 weeks. In contrast, the weight changes increased significantly at $58^{\circ} \mathrm{C}$ degradation of samples (around 20-40\%). So, it is apparent that a hydrolysis is very slow at ambient temperature for neat PLA and nanocomposites. It is because of the extensive changes of micro-structural and the rearrangement of molecular, allowing more absorption of water into the polymer matrix. The dimensions of micro holes are relatively high at high temperature degradation of $58^{\circ} \mathrm{C}$ confirming the high degradation level at the high degradation temperature (Fukushima et al., 2011).

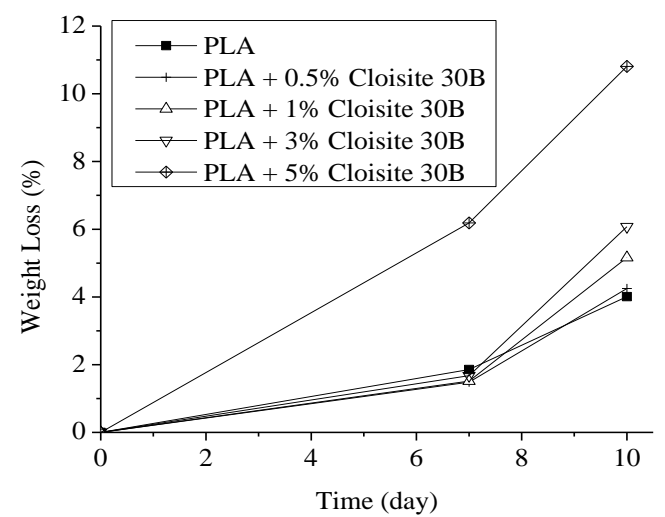

Fig. 5 Percent weight loss of neat PLA and PLA-Cloisite 30B nanocomposites with variable composition of clays.

Fig. 5 shows that the weight loss increases with the increasing composition of clay. These results are in accordance with those reported by Singh et al. (2012) that the neat PLA has a slow biodegradation rate (maximum $17 \%$ weight loss in 240 days). On the contrary, nanocomposites have high biodegradation rate. The hydrolytic degradation is accelerated in the presence of excess hydroxyl groups and the presence of terminal hydroxylated edge groups. Similar results were reported also from Fukushima et al. (2013) in PLAMontmorillonite (CLO30B) and PLA-Fluoro-hectorite (SOMMEE). At higher composition of clay, biodegradation process is accelerated due to catalysis by the hydroxyl end groups of silicate layers in the PLA matrix. Moreover, the high content of clays causes the highwater absorption of nanocomposites, resulting in fast hydrolytic degradation. Accordingly, the water absorption plays an important role in the degradation rate of the nanocomposites. In this study, higher clay contents increase the water absorption of nanocomposites. Higher water absorbed to nanocomposites will degrade nanocomposite more rapidly. In addition, the good interaction leads to an increase amorphous zone (Singh et al., 2012). After 10 days of biodegradation in compost instrument, the weight loss of the neat PLA and the nanocomposite with the addition of 5 wt. $\%$ of Cloisite $30 \mathrm{~B}$ are $4.0 \%$ and $10.8 \%$, respectively. In comparison with the nanocomposite with the addition of $0.5 \%$ by weight of Cloisite 30B, the weight loss of 5\% Cloisite 30BPLA nanocomposite increases about $154.43 \%$. 


\section{CONCLUSION}

Nanocomposites were successfully synthesized using melt extrusion technique by direct mixing of clays (Cloisite $30 \mathrm{~B}$ or commercial bentonite) and polymer matrix using single-screw extruder. From the result of XRD analysis, nanocomposite structures were partially exfoliated. The addition of clay increased the mechanical properties of the nanocomposites at low clay composition. The PLA-commercial bentonite nanocomposite has better tensile strength than the PLA-Cloisite 30B nanocomposites. The tensile strength of $0.5 \mathrm{wt} \%$ of commercial bentonite-PLA nanocomposite increase about $23.25 \%$ compared to the neat PLA. The addition of clays also influences the water absorption properties. The addition of clays up to $1 \mathrm{wt} . \%$ increased water absorption properties, because of the tortuous path increased for water diffusion through the nanocomposite. Thus, the $0.5 \mathrm{wt} \%$ of commercial bentonitePLA nanocomposite has the best properties which has high tensile strength and low water absorption. Furthermore, the biodegradation rate of nanocomposite also higher than the neat PLA. The weight loss of the neat PLA and the nanocomposite with the addition of $5 \mathrm{wt} . \%$ of Cloisite $30 \mathrm{~B}$ are $4.0 \%$ and $10.8 \%$, respectively.

\section{ACKNOWLEDGEMENT}

This study was partially funded by LPDP, Ministry of Finance, Indonesia, through LPDP scholarship and by SINAS grant through Ministry of Research, Technology and Higher Education, Indonesia.

\section{REFERENCES}

Awal, A., Rana, M., Sain, M. 2015. Thermomechanical and mechanical properties of cellulose reinforced PLA bio-composites. Mechanics of Material, 80, 87-95.

Bikiaris, D., N. 2013. Nanocomposites of aliphatic polyesters: An overview of the effect of different nanofillers on enzymatic hydrolysis and biodegradation of polyesters. Polymer Degradation and Stability, 98, 1908 1928.

Chow, W., S., Leu, Y., Y., Mohd. Ishak, Z., A. 2014. Water absorption of poly (lactic acid) nanocomposites: Effects of nanofillers and maleated rubbers. Polymer-Plastics Technology and Engineering, 53, 858-863.

Chow, W., S., Mohd. Ishak, Z., A., Ishiaku, U., S., Karger-Kocsis, J., Apostolov. 2004. The effect of organoclay on the mechanical properties and morphology of injection-molded polyamide 6/polypropylene nanocomposites. Journal of Applied Polymer Science, 91, 175-189.

Farah, S., Anderson, D., G., Langer, R. 2016. Physical and mechanical properties of PLA, and their functions in widespread applications-A comprehensive review. Advanced Drug Delivery Reviews, 107, 367-392.

Fukushima, K., Tabuani, D., Dottori, M., Armentano, I., Kenny, J. M., Camino, G. 2011. Effect of temperature and nanoparticle type on hydrolytic degradation of poly (lactic acid) nanocomposites. Polymer Degradation and Stability, 96, 2120-2129.

Fukushima, K., Tabuani, D., Arena, M., Gennari, M., Camino, G. 2013. Effect of clay type and loading on thermal, mechanical properties and biodegradation of poly (lactic acid) nanocomposites. Reactive \& Functional Polymers, 73, 540-549.
Ma, F., Lu, X., Wang, Z., Sun, Z., Zhang, F., Zheng, Y. 2011. Nanocomposites of poly(L-lactide) and surface modified magnesia nanoparticles: Fabrication, mechanical property and biodegradability. Journal of Physics and Chemistry of Solids, 72, 111-116.

Lai, J., C., H., Rahman, M., R., Hamdan, S. 2017. Comparative studies of thermo-mechanical and morphological properties of polylactic acid/fumed silica/clay (1.28E) and polylactic acid/fumed silica/clay (1.34TCN) nanocomposites. Polymer Bulletin, 75, 135-147.

Lai, S., Wu, S., Lin, G., Don, T. 2014. Unusual mechanical properties of meltblended poly (lactic acid) (PLA)/clay nanocomposites. European Polymer Journal, 52, 193-206.

Lee, Y., H., Park, C., B., Sain, M., Kontopoulou, M., Zheng, W. 2007. Effects of clay dispersion and content on the rheological, mechanical properties, and flame retardance of HDPE/clay nanocomposites. Applied Polymer Science, 105, 1993-1999.

Ma, F., Lu, X., Wang, Z., Sun, Z., Zhang, F., Zheng, Y. 2011. Nanocomposites of poly(l-lactide) and surface modified magnesia nanoparticles: Fabrication, mechanical property and biodegradability. Journal of Physiscs and Chemistry of Solids, 72, 111-116.

Molinaro, S., Romero, M., C., Boaro, M., Semidoni, A., Lagazio, C., Morris, M., Kerry, J. 2013. Effect of nanoclay-type and PLA optical purity on the characteristics of PLA-based nanocomposite films. Journal of Food Engineering, 117, 113-123.

Ollier, R., Rodriguez, E., Alvarez, V. 2013. Unsaturated polyester/bentonite nanocomposites: Influence of clay modification on final performance. Composites Part A: Applied Science and Manufacturing, 48, 137-143.

Ozdemir, E., Lekesiz, T., O., Hacaloglu, J. 2016. Polylactide/organically modified montmorillonite composites; effects of organic modifier on thermal characteristics. Polymer Degradation and Stability, 134, 87-96.

Paramitha, T., Sitompul, J., P., Lee, H. W. 2018. The effect of organobentonites from spent bleaching earth (SBE) and commercial bentonite on nanocomposite properties. International Journal of Engineering \& Technology, 7(4), 2000-2005.

Phuong, V., T., Lazzeri, A. 2012. "Green" biocomposites based on cellulose diacetate and regenerated cellulose microfibers: Effect of plasticizer content on morphology and mechanical properties. Composites: Part A. 43, 22562268.

Pirani, S., I., Krishnamachari, R., Hashaikeh, R. 2014. Optimum loading level of nanoclay in PLA nanocomposites: Impact on the mechanical properties and glass transition temperature. Journal of Thermoplastic Composite Materials, 27, 1461-1478.

Rahman, M., M., Islam, M., S., Li, G., S. 2018. Development of PLA/CS/ZnO nanocomposites and optimization its mechanical, thermal and water absorption properties. Polymer Testing, 68, 302-308.

Ray, S., S., Yamada, K., Okamoto, M., Ogami, A., Ueda, K. 2003. New Polylactide/Layered Silicate Nanocomposites. 3. High-Performance Biodegradable Materials. Chemistry of Materials, 15, 1456-1465.

Ray, S., S., Yamada, K., Okamoto, M., Ueda, K. 2003. Control of biodegradability of polylactide via nanocomposite technology. Macromolecular Materials and Engineering, 288, 203-208.

Rhim, J., Hong, S., Ha, C. 2009. Tensile, water vapor barrier and antimicrobial properties of PLA/nanoclay composite films. LWT-Food Science and Technology, 42, 612-617.

Singh, N., K., Purkayastha, B., P., D., Panigrahi, M., Gautam, R., K., Banik, R., M., Maiti, P. 2012. Enzymatic degradation of polylactide/layered silicate nanocomposites: Effect of organic modifiers. Journal of Applied Polymer Science, 127, 2465-2474.

Siracusa, V., Rocculi, P., Romani, S., Rosa, M., D. 2008. Biodegradable polymers for food packaging: a review. Trends in Food Science \& Technology, 19, 634-643.

Yew, G., H., Yusuf, A., M., M., Ishak, Z., A., Ishiaku, U., S. 2005. Water absorption and enzymatic degradation of poly (lactic acid)/rice starch composites. Polymer Degradation and Stability, 90, 488-500.

Zaidi, L., Bruzaud, S., Bourmaud, A., Mederic, P., Kaci, M., Grohens, Y. 2010. Relationship between structure and rheological, mechanical and thermal properties of polylactide/cloisite 30B nanocomposites. Journal of Applied Polymer Science, 116, 1357-1365. 